\title{
Brief Introduction to Enterprise Human Resources Management by Projects
}

\author{
Feipeng Liu \\ Management Department, Shaanxi Vocational and Technical College, Xi'an, 710100, China
}

Keywords: Enterprise. Managements of human resources. Projectized

\begin{abstract}
Nowadays, the global economy has entered the era of knowledge-based economy that is also called the new era of transforming knowledge to tangible benefit. One of the vital methods to achieve this transformation is management by projects. This thesis analyzes the related conception and characteristics of enterprise human resources management by projects, sets examples of the advantaged of enterprise human resources management by projects and discusses the methods of enterprise human resources management by projects.
\end{abstract}

\section{Introduction}

In today's society, knowledge-based economy is already ready and impels human resources management to be a primary element which directly influences enterprise performance step by step. Without efficient human resources management, an enterprise is impossible to realize the goals of human resources management. Therefore, after the transformation from personnel management to human resources management, Chinese enterprises introduced plenty of advanced conceptions and instruments of human resources management, but the actual effect is not as good as expected. Enterprise human resources management is facing a series problems needed to be solved. In the author's opinion, under this circumstance the idea of human resources management by projects, a unique and complete scientific system which has successful experience in other fields, should be brought in to provide new method for modern enterprise human resources management.

\section{The related conceptions and characteristics of the project of enterprise human resources}

Management by projects is a methodology that applies systemized theory and methods to design, organize, coordinate and control the project resources based on the efforts of projector manager and all staff so as to manage the specific goals of projects. Although there are some similarities between management by projects and general management, management by projects is not with the stability as normal tasks but has its own characteristics. The first one is non-repeated. A new project requires new management and different stages of development of the same project have different forms of management, so management by projects needs to explore continuously. The second one is unpredicted. The final result of projects is vague at first, and it may be the opposite. The third one is unrestricted. Management by projects is to management people from different posts organized temporarily. Because everyone undertakes different tasks, the structure of departments is loose. The forth one is with organizational culture. Organizational culture, forming by a series of rules, scopes and conception, is prevalent various life ways in organizations. That's the rules of methods, scopes of work and ways about how it works in certain organization.

The project of enterprise human resources mainly refers to one-time work which aims at creating special products or service of human resources. For example, arranging a job fair or training by an enterprise, establishing or innovating performance management system or salary distribution system, implementing institutional reform and carrying out competition for a higher position are all regarded as different projects of human resources. There are several outstanding features of projects of human resources. One is the feature of temporariness which means that a project of human resources has exact time of beginning and ending. A project is repeated and without exact time of beginning and ending is not a project of human resources but a daily work. Another situation is that this project is 
hard to finish because of many reasons after it began, then this project can be regarded as a project of human resources but it is a failure. Second is the feature of uniqueness. That is to say, every project of human resources in an enterprise is unique. It is successful for human resources work which does not have measurements if they match to the practice. The most important factor is to find the right way for every single different case. It won't work if you just copy old ways. Third is the feature of step-by-step process. The obvious features of products with uniqueness are formed gradually. In the early time of projects management, the above features were defined initially and made confirmed clear and detailed definition after more adequate and comprehensive cognition of products of the enterprise by the work team of this project.

\section{The advantages of enterprise human resources management by projects}

First, it can assure the schedule and quality of the completion of human resources projects. The result-oriented management by projects pays close attention to the results. Thus, introducing the method of management by projects into enterprise human resources work can better guarantee that the results meet the requirements from different aspects. To achieve the enterprise strategy goals, project organizers can divide the general goal into several small objectives which can be done by the next-level project team or department through the project way. And the next project team or department can divide their objective into smaller one to the third-level team. The result-oriented thought of management by projects can ensure the schedule and quality of the completion of the whole task. Meanwhile, if add the cost indicator to enterprise human resources management by projects, the total cost of management by projects can be controlled effectively.

Second, it can take the most beneficial opportunity in the reform of enterprise human resources to improve the efficiency of the reform. Management by projects emphasizes cooperation and team spirit which stand out during the process of execution and management of enterprise projects and requires the related staff to work together and contribute in achieving the common goals. At the same time, management by projects will also restructure resources accordingly. Enterprises shall utilize the most suitable resources among all kinds of integrated resources of related organizations needed by human resources projects. In this way, it can grasp the best chance to increase the efficiency of the human resources reform.

Third, it can well control enterprise human resources management operating costs. The team of enterprise human resources management by projects which is formed based on the needs of projects is an open group, adjusting projects organizations and team members flexibly. That helps keep the amount of members, professional background and working time adequately flexible, which can improve the efficiency of enterprise human resources management work. When the project is finished, this team will be dismissed and back to their original positions, so the enterprise organization operating costs are reduced. In the meantime, the conception of management by projects thinks that it is inevitable to face various emergencies because of its flexibility, so enterprise management projects directors are not required to make a perfect plan but to adjust corresponding plans according to the changes of situation timely in order to ensure the goals of projects can be achieved to maximum extent. It is so important to enterprise human resources management. This characteristic of management by projects provides applicability for the variability of unpredicted factors such as involved employees' psychology and enterprise culture. In fact, introducing the method of management by projects to enterprise human resources management treats salary plan and performance evaluation as special projects, which helps enterprise inner departments strict to time schedule, utilize resources more effectively to the most emergent affairs and keep corresponding risks steady. The method of management by projects also can make human resources management easier and avoid panic when facing accidental events.

\section{The methods of enterprise human resources management by projects}


Enterprise human resources management by projects is pointed out relative to traditional human resources functional management. It is a human resources management activity designed on the basis of the operation of specific projects, focusing on the development of enterprises and its staff. It is discussed from the below three aspects. One is to observe in view of designation. Enterprise human resources management by projects is set specific projects as supporting points but not to be divided into normal functional modules such as recruitment, evaluation and salary. Another one is to observe in view of management system. Enterprise human resources management by projects should aim at successful operation of projects including operation modes, confirmation of performance goals, selecting team members, management of project performance and promotional incentives. The last one is to observe in view of operation system. Projects managers are the main power of enterprise human resources management by projects, being in full charge of selecting evaluating and stimulating participants. As a kind of new management models, enterprise human resources management by projects is a systemized project as well. Here, I just try to describe the main contents of implementation of enterprise human resources management by projects, hoping it can be enlightenment for enterprise managers.

The first stage is to establish talent team for reserved projects actively. Because enterprise human resources management by projects is applied on growing enterprises, naturally recruiting the talent has particularity. On the one hand, the scope of core professional members and talented managers should be strictly limited. At the same time, the professional ethics and loyalty of core talents should be verified carefully. On the other hand, the team shall recruit reasonable numbers of comprehensive talents with vague professional directions. During the recruitment, plasticity of candidates should be paied attention to. The ways of recruitment can be full-time or part-time according to the actual needs.

The second stage is to get approval of projects and equip appropriate talents to projects. The work needs project committee made up of senior leaders and one to three core professional talents to explore the operation ways, management goals and the requirements of project managers, etc. by holding a public project managers assembly to announce specific requirements and suitable conditions of candidates, in which the whole staff in the enterprise are qualified to take part in. the project committee should evaluate applicants' qualification according to their competition speech to select the right directors of the project who are responsible for building the project team of which the members can be the inner staff or recruited outside by directors.

The third stage is to carry out the work of project management and supervision. The work is drawing up a plan of the project, allocating responsibilities to project members, monitoring the process of project operation and evaluating project members by project directors and so on. Project directors can have project committee to give guidance or anticipate in outside coordination and communication if it is necessary. The project committee should monitor the conditions of project operation on the basis of the difficult parts of the projects and communicate and handle this issue with project directors immediately.

The fourth stage is to comprehensively evaluate the condition of project operation against defaulted individual objectives to clarify the overall method of reward and punishment. Please note that enterprise project reward should be made full payment at the end of the project within one month and can be reserved a small part at discretion and paid later if the project members need follow-up investigation. However, the delay period should not be more than three months and appropriate reasons should be given. The comprehensive assessment should be done regarding to the size of projects, difficulty level and actual condition of completion and issue corresponding grade certificates and adjust their salary respectively.

The fifth stage is that the project directors should allocate the reward funds according to the total amount of project reward and the contribution of participants. It is worthy to note that bonus with both pertinence and promptness can be treated as incentives, so payment of bonus or commission should be made within one month. The allocated amount of bonus should be based on the working time and the importance and difficulty of tasks of participants. And the over-working time because of personal reasons should be regarded as invalid. 
The sixth stage is to record the summary of experience of operation and documents including the below two aspects: projects directors prepare and arrange documents of operation modes and management experience, etc. managed by project directors; human resources department manage the documents of staff performance and bonus which are the chief evidence of salary and promotion in the future.

\section{Conclusion}

All in all, management by projects in human resources management is evitable trend of development and meets the need of development of the times. If enterprise human resources managers master the related knowledge and skills about management by projects and supervise every project in the way of management by projects, the working efficiency can be improved greatly and the final effects can be assured. It is much beneficial for the human resources management work carried out on a larger scale. Among human resources management, the reform of salary system, recruitment, training activities, adjustment of organization structure, performance evaluation and establishment of enterprise culture can actually be classified into individual human resources management project and operated as the way of management by projects.

\section{References}

[1] Li Hongmin. A Brief Introduction to Core Management of International Enterprise Human Resources Management by Projects, Modern Commence, 2007(27)

[2] He Yuan, Zhang Luqi. The Thought of Enterprise Human Resources Management by Projects, Jiangsu Construction Materials, 2008(2)

[3] Wen Min. The Refinery of Contradictions and Resolvation of the Integration of Projects and Human Resources Equipment, Journal of Petroleum and Chemical Management Cadre Institution,2012(1)

[4] Wang Haiqing. A Brief Introduction of Human Resources Management by Projects, Journal of Jilin Institution of Chemical Industry, 2012(10)

[5] Lin Ruibin. Reflection on Guarantee Work of Construction of Large Refining Project and Human Resources, Economist,2013(6). 